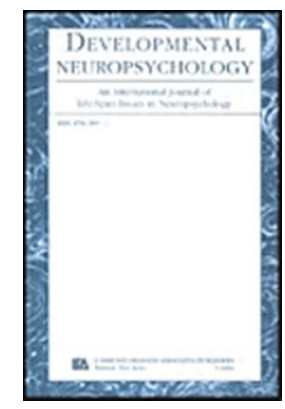

\title{
Delayed development of neural language organization in very preterm born children
}

\begin{tabular}{|r|l|}
\hline Journal: & Developmental Neuropsychology \\
\hline Manuscript ID: & HDVN-2014-0033 \\
\hline Manuscript Type: & Original Article \\
\hline Keywords: & $\begin{array}{l}\text { fMRI, lateralization, language network, premature birth, phonological } \\
\text { detection }\end{array}$ \\
\hline
\end{tabular}

\section{SCHOLARONE ${ }^{m}$} Manuscripts 


\section{Developmental Neuropsychology}

Running head: LANGUAGE ORGANIZATION IN VERY PRETERM CHILDREN

1

2

3

4

5

6

7

8

9

10

11

12

13

14

15

16

17

18

19

20

21

22

23

24

25

26

27

28

29

30

31

32

33

34

35

36

37

38

39

40

41

42

43

44

45

46

47

48

49

50

51

52

53

54

55

56

57

58

59

60
Delayed development of neural language organization in very preterm born children

Words: Abstract: 100, Manuscript: 4061

Submission to: Developmental Neuropsychology

Article Type: Original Article

URL: http://mc.manuscriptcentral.com/hdvn Email: dlmolfese@mac.com 
LANGUAGE ORGANIZATION IN VERY PRETERM CHILDREN

\begin{abstract}
This study investigates neural language organization in very preterm born children compared to control children and examines the relationship between language organization, age and language performance. Fifty-six preterms and 38 controls (7-12y) completed an fMRI language task. Lateralization and signal change were computed for language-relevant brain regions. Younger preterms showed a bilateral language network whereas older preterms revealed left-sided language organization. No age-related differences in language organization were observed in controls. Results indicate that preterms maintain atypical bilateral language organization longer than term born controls. This might reflect a delay of neural language organization due to very premature birth.
\end{abstract}

Keywords: fMRI, lateralization, language network, premature birth, phonological detection 
LANGUAGE ORGANIZATION IN VERY PRETERM CHILDREN

Delayed development of neural language organization in very preterm born children

Very preterm born children ( $<32$ weeks of gestation) represent $1-2 \%$ of all live births in developed countries (Saigal \& Doyle, 2008). The increased quality of neonatal intensive care has led to higher survival rates of these children over the last 20 years (Saigal \& Doyle, 2008). Nevertheless, very preterm birth is often accompanied by moderate to severe cognitive problems (Saigal \& Doyle, 2008).

Very preterm born children and/or children with very low birth weight $(<1500$ gram) are at increased risk of language problems throughout childhood, probably due to abnormal structural and functional development (Rushe, 2010). Delays in the acquisition of vocabulary, quality of word use, syntax and morphology at the age of 2 years, and worse expressive and receptive language skills as well as problematic phonological processing at school age have been described (Barre, Morgan, Doyle, \& Anderson, 2011; Foster-Cohen, Edgin, Champion, \& Woodward, 2007; Sansavini et al., 2007; Wolke \& Meyer, 1999). For complex language functions a meta-analysis suggested that deficits even increase between 3 and 12 years of age (van Noort-van der Spek, Franken, \& WeisglasKuperus, 2012). Hence, it remains unclear whether language problems increase with age due to higher cognitive demands or whether language problems in very preterm born children indicate a delay in language acquisition which diminishes with age (Rushe, 2010).

Alterations in the cognitive development of very preterm born children are likely to be underpinned by structural abnormalities. A substantial part of myelination, proliferation and organization of synapses normally occurs in the last weeks of pregnancy (Gressens, 2000). As very preterm born children are born before these important processes are completed, structural abnormalities are likely to occur (Counsell, Rutherford, Cowan, \& Edwards, 2003). Structural alterations can influence cognitive outcome. Carreiras et al. (2009) found that a smaller volume of the corpus callosum may have implications for reading comprehension throughout adulthood. Likewise, structural development is likely to be associated with functional organization in the brain.

Clinical functional magnetic resonance imaging (fMRI) studies suggest different language organization in preterm born children when compared with same-aged controls. In term born control children, several studies suggest that language organization is extensive and bilateral, with an 
LANGUAGE ORGANIZATION IN VERY PRETERM CHILDREN

increase in language lateralization to the left hemisphere with increasing age, which is likely associated with higher Verbal-IQ (Everts et al., 2009; Holland et al., 2001; Holland et al., 2007). In very preterm born children, studies suggest alternative neural language organization: 12-year-old very preterm born children showed a more extended auditory processing network during a passive listening task when compared with a control group (Ment et al., 2006). Increased utilization of the right hemisphere for language-related tasks is reported in very preterm born adolescents (Gozzo et al., 2009; Rushe et al., 2004). Another study showed that very preterm born children used the neural network for semantic processing which controls engaged to process meaningless phonological sounds, suggesting that very preterm born children use different language pathways than controls (Peterson et al., 2002). Interestingly, the lower the language performance in very preterm born children, the likelier is the engagement of auxiliary right hemisphere language regions (Myers et al., 2010). Taken together, these studies suggest alternative language organization in very preterm born children and raise the question if age and language performance influence language organization in both very preterm and term born control children.

The present study investigates language organization in very preterm born children compared to term born controls and sheds light on the effect of age and performance on neural language organization. We hypothesize that very preterm born children show alterations in language organization compared to same-aged controls. Language organization in very preterm born and term born control children underlies age-dependent changes and is related to the language performance level.

\section{Method}

The present study contributes to a clinical trial examining neuropsychological development of very preterm born and term born control children. The study protocol was approved by the local ethics committee. All children and caregivers provided informed written consent for the research and publication of the results prior to participation, consistent with the Code of Ethics of the World Medical Association (Declaration of Helsinki). 
LANGUAGE ORGANIZATION IN VERY PRETERM CHILDREN

\section{Participants}

Medical reports of all very preterm ( $<32$ weeks of gestation) and/or low birth weight $(<1500$ gram) children born between 1998 and 2003 at the Children's University Hospital in XX were reviewed. Native German speakers aged 7 to 12 years with normal neonatal ultrasound (no or mild periventricular leukomalacia, grade I or II; no or mild neonatal cerebral lesions, hemorrhage grade I), no chronic illness, no pervasive developmental disorders, and Full-scale $I Q>85$ in the neuropsychological follow-ups were included. We chose Full-scale $I Q>85$ for our study sample to represent the largest population of very preterm born children, namely those with an IQ within the normal range and to avoid cognitive heterogeneity which might impact the generalizability of the results (Johnson et al., 2009). 247 children fulfilled the inclusion criteria and were contacted, 75 children agreed to participate in the study. Sixty very preterm born children completed the neuropsychological assessment and the fMRI task. Four very preterm born children were excluded from the analysis (technical problems $n=2$, low compliance during the $\mathrm{fMRI}$ task with $<50 \%$ responses $n=2)$. Finally, fifty-six very preterm born children were included in the study.

Term born controls were recruited by means of announcements in the hospital. Native German speakers aged 7 to 12 years with no chronic illness, no pervasive developmental disorders, and Full-scale IQ>85 in the neuropsychological assessments were included. Forty-two controls completed the study; four children were excluded from further analysis (technical problems $n=1$, low compliance during the fMRI task with $<50 \%$ responses $n=3$ ). Finally, thirty-eight controls were included in the study.

\section{Study procedure}

Children completed a neuropsychological test battery at the first appointment, and at the second appointment underwent an fMRI assessment at the Department of Diagnostic and Interventional Neuroradiology, University Hospital XX (mean time between neuropsychological assessment and MRI was 11 days, ranging from 1 to 33 days).

\section{Neuropsychological assessment}

For the present study, Full-scale IQ of the short form of the WISC-IV (Crawford, Anderson, Rankin, \& MacDonald, 2010) and three language performance measures, namely Verbal-IQ, verbal 


\section{Developmental Neuropsychology}

LANGUAGE ORGANIZATION IN VERY PRETERM CHILDREN

fluency and reading comprehension were selected from the neuropsychological test battery. Verbal$I Q$, the verbal comprehension index of the WISC-IV, constitutes of three verbal subtests: similarities, vocabulary and comprehension (Crawford et al., 2010). In the verbal fluency test, children were asked to name as many words as possible beginning with the letter ' $F$ ', 'A' or 'S' during 60 seconds (Delis, Kaplan, \& Kramer, 2001). Reading comprehension was assessed using the ELFE (Ein Leseverständnistest; Lenhard, 2006) which examines word reading (choosing one out of four words which matches a pictured object) and sentence reading (choosing one out of five words in order to complete a sentence). For both subtests, performance was calculated based on the number of correctly solved trials after two minutes $\left(1^{\text {st }}-4^{\text {th }}\right.$ graders $)$ or three minutes $\left(5^{\text {th }}-6^{\text {th }}\right.$ graders $)$. Raw scores were transformed into age-corrected scaled scores (with higher scores reflecting better performance). Handedness was determined by a telephone interview prior to the first assessment. Socioeconomic status (SES) was defined as the mother's and father's education levels at the time of the neuropsychological assessment (no high school graduation=1, high school graduation=2, college graduation $=3$, university degree $=4$ ).

\section{fMRI assessment}

The vowel detection task is a well-established fMRI-based method for detecting the neural network of internal word generation and phonological detection (Everts et al., 2009; Wilke et al., 2006). The task is known to reliably activate inferior frontal and superior temporal regions in children aged 6 to 16 years (Everts et al., 2009; Wilke et al., 2006). Children were asked if a certain phoneme (the German [i] as in English 'bee') was part of the name of an object presented on the screen (activation condition). The baseline condition consisted of unnamable images (fractals), the smaller of which was or was not 'like a piece of a puzzle' -- a part of the larger image. Response buttons allowed for 'yes' (left hand) and 'no' (right hand) responses. Left and right hand responses were balanced (50:50) between both conditions. The fMRI task was presented in a block design (activation condition: five blocks; baseline condition: six blocks; each block consisted of six trials, resulting in 66 presented trials, one block $=30$ seconds, total task duration $=5$ minutes, 30 seconds).

Children were introduced to the scanner surrounding and prepared for the fMRI task. All children demonstrated understanding of the task before performing the task inside the scanner. Following the MRI scan, children completed a short questionnaire designed to assess their feelings 
and the difficulty level of the task during the scan, e.g. "how distressing was the fMRI task for you?" and "how difficult was the fMRI task?". Responses were provided on a 5-point scale ranging from 0 to 4 , with a low score reflecting less distress or difficulty.

\section{fMRI data acquisition}

Data were acquired on a Verio3-T whole body scanner (Siemens Erlangen, Germany) equipped with a $40 \mathrm{mT} / \mathrm{m}$ (200 mT/m-ms) gradient system and a CP standard head coil (12 channels). The scanner was equipped with the Syngo MR 2002B (VA17) software. Anatomical imaging was obtained using a T1-weighted, 3D-MPRAGE sequence (TR $2300 \mathrm{~ms}$, TE $2.98 \mathrm{~ms}$, FoV 256, $1 \mathrm{~mm}$ voxel resolution, 160 contiguous sagittal slices). Functional images were acquired using a multi-slice single-shot T2-weighted EPI sequence, with 40 interleaved axial oblique slices, positioned in-line with the bicommissural axis (TR $5000 \mathrm{~ms}$, no delay, TE $30 \mathrm{~ms}$, TA $5 \mathrm{~min} 35 \mathrm{sec}, 3 \mathrm{~mm}$ resolution, 108 measurements).

\section{Data analyses}

fMRI data analysis. Data were analyzed using SPM8 software (Wellcome Trust Centre for Neuroimaging, London, UK) running in Matlab 7.1 (Mathworks, Natick, MA, USA). The first 12 scans of the function series (first block of the baseline condition) were deleted to allow for stabilization of longitudinal magnetization. After slice timing, functional images were spatially realigned and unwarped using the individually acquired B0 fieldmap, correcting for EPI and motion *B0 distortions (Andersson, Hutton, Ashburner, Turner, \& Friston, 2001). Children who moved more than 1 voxel size in any direction were excluded. Data were normalized using custom-generated pediatric reference data (TOM-toolbox; Wilke, Holland, Altaye, \& Gaser, 2008) Images were smoothed by a $9 \mathrm{~mm}$ Full Width at Half Maximum Gaussian kernel. First level analyses were conducted using the General Linear Model contrasting the active and baseline conditions and the resulting contrast images were entered into a random-effect second level analysis. To examine whole-brain language organization, one-sample t-tests with $p<.05$ (familywise error rate, FWE corrected) and an extent threshold of $k>60$ were computed for very preterm born children and controls. In order to investigate age effects on language organization, younger and older age groups were built, computing the lower and upper age terciles of the respective group. For age group analyses, a threshold of $p<.001$ (without correction; $k>20$ ) was used. 
LANGUAGE ORGANIZATION IN VERY PRETERM CHILDREN

Percent signal change (PSC). In order to quantify neural activation in circumscribed regions involved in language processing, PSC was based on first level statistics and was calculated as

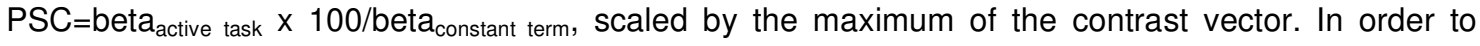
calculate PSC, regions of interest of the main activation clusters in the control sample were defined, resulting in left and right frontal and left and right temporal regions of interest.

Lateralization index (LI). An LI was computed to compare the asymmetry of activation over both brain hemispheres. Language-relevant bilateral frontal and temporal regions of interest were chosen from the LI-toolbox. The LI-toolbox calculates individual t-maps using a bootstrapping approach (positive $\mathrm{LI}$ of $>0.2=$ left-sided dominance, negative $\mathrm{LI}$ of $<-0.2=$ right-sided dominance, $\mathrm{LI} \geq-$ 0.2 and $\leq 0.2=$ bilateral activation (Wilke \& Lidzba, 2007; Everts et al., 2009).

Statistical analyses of the behavioral data. Statistical analyses were performed using IBM SPSS Statistics 21.0. As not all of the variables were distributed normally, non-parametric tests were used. In order to compare group characteristics of the preterm and control group, Mann-Whitney $U$ tests were computed for continuous variables (age, SES, Full-scale IQ, Verbal-IQ, verbal fluency, word reading, sentence reading, LI, PSC) and a two-sided chi-square test was conducted for the categorical variable sex. To test for associations between language organization (PSC and LI), age and language performance, Spearman's correlations were performed (one-sided).

\section{Results}

\section{Demographic data and handedness}

Demographic data is presented in Table 1. Very preterm born children and controls were comparable with regard to age and sex. Socioeconomic status was significantly lower in very preterm born children's parents. To investigate the effect of handedness on language organization, we performed group analyses including left-handed and ambidextrous children (left-handed: very preterm born children $n=7$, controls $n=4$; ambidextrous: preterms $n=4$, controls $n=2$ ) versus right-handed children (right-handed: preterms $n=45$, controls $n=32$ ). Children with atypical handedness activated the same language regions as children with typical handedness. It has been reported that the rate of children with left-sided language organization is independent of handedness (Szaflarski et al., 2012). Therefore, children with atypical handedness were included in the further analyses. Six of the very 
LANGUAGE ORGANIZATION IN VERY PRETERM CHILDREN

preterm born children received language therapy with a mean duration of 20.5 months. These children did not differ from their peers with regard to fMRI language organization.

\section{Movement}

Mean translational movement across the $\mathrm{X}, \mathrm{Y}$, and $\mathrm{Z}$ head directions was $0.92 \mathrm{~mm}(S D 1.05)$ in the very preterm group and $0.61 \mathrm{~mm}(S D$ 0.48) in the control group $(U=953.0, Z=-.720, p=.471)$. No participant had to be excluded because of extensive head movement.

\section{Task accuracy}

Task accuracy was not assessed because the children generated words internally and hence validation of task performance was not possible (a 'ship' can as well be thought of as 'boat' or 'yacht'). Therefore, task accuracy was only considered as a compliance measure. The majority of the children found the fMRI task not very difficult and not tiring (provided a rating of 0 or 1 on a 5-point scale). 21 children (20\%) found the task moderately difficult (i.e. provided a rating of 2) and 18 children (17\%) found the task moderately tiring (i.e. provided a rating of 2). There was no difference in perceived difficulty or effort between very preterm born children and controls.

\section{Group comparisons}

Very preterm born children and controls both revealed main activation clusters in the left inferior and middle frontal gyrus, the left superior temporal gyrus, the upper part of the left superior frontal gyrus and the left angular gyrus (FWE corrected, $p<.05$, voxel threshold k>60; Figure 1 A). To determine the influence of age on language organization, group analyses were conducted for younger (lower age tercile of the group) and older children (upper age tercile) separately (see Table 1). Younger very preterm born children showed a wider distribution of activity in bilateral fronto-temporal areas and larger activation clusters than younger controls, who mainly activated left-sided frontal areas. Older very preterm born children and older controls showed similar activation clusters in left language related fronto-temporal regions ( $p<.001$, voxel threshold k>20 voxels, Figure 1$)$.

\section{Lateralization index}

Frontal and temporal $\mathrm{LI}$ are shown in Table 1. Overall, very preterm born children and controls did not differ with regard to LI. To analyze the age influence on language organization, 
LANGUAGE ORGANIZATION IN VERY PRETERM CHILDREN

correlations between age and LI were conducted (Table 2). In very preterm born children, there was a significant positive correlation between age and temporal $\mathrm{LI}(r(56)=.355, p=.004)$, which was mainly driven by the younger children (Figure 2). Age did not correlate with frontal LI in very preterm born children. In controls, age correlated marginally with frontal $\mathrm{LI}(r(38)=.218, p=.095)$ but not with temporal LI.

\section{Percent signal change}

Very preterm born children and controls did not differ with regard to PSC. PSC did not correlate with age in very preterm born children and controls.

Sex did not influence language lateralization or PSC, neither in very preterm born children nor in controls.

\section{Relationship between language organization and language performance}

Mean cognitive performance was significantly worse in very preterm born children than controls (Table 1), with eight very preterm born children showing Full-scale IQ $<90$, as compared to none among controls. However, very preterm born children's and controls' mean language performances were within the normal range.

In very preterm born children, temporal LI correlated with word reading $(r(56)=.256, p=.035)$ and frontal LI marginally correlated with sentence reading $(r(56)=.225, p=.066)$. No correlations between temporal or frontal $\mathrm{LI}$ and IQ, Verbal-IQ and verbal fluency were found. No correlations between PSC and language performance occurred.

In controls, a positive correlation occurred between frontal LI and Full-scale IQ $(r(38)=.299$, $p=.034)$. A negative correlation between temporal $\mathrm{LI}$ and sentence reading was found $(r(38)=-.295$, $p=.043)$. No correlation occurred between frontal and temporal $\mathrm{LI}$ and Verbal-IQ, verbal fluency and word reading. A negative correlation was found between right frontal PSC and Full-scale IQ $(r(36)=-$ .281, $p=.044)$. No other correlations between PSC and performance occurred in the other ROls.

Overall, no correlation between age, LI, PSC, and language performance reached statistical significance at $p<0.05$ after Bonferroni correction for multiple testing. 
LANGUAGE ORGANIZATION IN VERY PRETERM CHILDREN

1

2

3

4

5

6

7

8

9

10

\section{Discussion}

In the present study, we describe characteristics of language organization in very preterm born children in comparison to same-aged term born controls and investigate the relationship between language organization, age and language performance. An age-dependent difference in language organization between very preterm born children and controls became evident: in very preterm born children at early school age, language was organized in a broad network extending over bilateral fronto-temporal brain regions. Older very preterm born children showed unilateral language organization over left fronto-temporal brain areas, resembling the language network of the total control sample. Accordingly, an age-dependent increase of activation asymmetry towards the left hemisphere was observed in very preterm born children, indicating more left-sided language organization with increasing age. These results suggest a shift towards typical left-sided language organization with age in very preterm born children, whereas in controls, typical left-sided language organization was already established at younger age.

Why do very preterm born children show bilateral language organization at early school age? A first possible explanation is that the recruitment of atypical bilateral language areas helps to compensate for structural or functional abnormalities that often follow very premature birth (Bates, 1999). A previous study showed that under certain circumstances atypical language organization can even be advantageous with regard to cognitive performance (Everts et al., 2010). A second explanation lies in the early intervention and speech and language therapies often applied to very preterm born children. The development from a bilateral to a more left-sided language organization might be a marker for the support and therapy received throughout childhood. A third explanation for the different formation of the neural language network is a possible maturational delay of very preterm born children. Our results suggest that alterations of the language network are only temporary at early school age whereas typical language organization is established once the structural and functional maturation has progressed (at about 11-12 years of age). Our results are in line with performance based data of the same cohort, which suggest a delay of executive functions in very preterm born children at early school age. This delay is no longer apparent at the age of 11-12 years (Ritter, Nelle, Perrig, Steinlin, \& Everts, 2013). Hence, a maturational delay at early school age but a catch-up of functional development by around 12 years of age offers a plausible explanation for the longer retention of atypical language organization in very preterm born children. 


\section{Developmental Neuropsychology}

LANGUAGE ORGANIZATION IN VERY PRETERM CHILDREN

A prolonged development of language organization is also reflected by neurostructural changes in very preterm born children. Age-dependent changes have been found in the volume of the corpus callosum, which supplies the association and language cortices (Thompson et al., 2000). Since the corpus callosum is crucial for the exchange between the hemispheres, its developmental changes are likely to influence the lateralization of cognitive functions. The corpus callosum volume is reduced in very preterm born adolescents and undergoes a different developmental trajectory in preterms and controls (Nosarti et al., 2004; Parker et al., 2008). Between the ages of 14 to 19 years a $3 \%$ increase of the callosal volume has been found in controls, compared to a $13 \%$ increase seen in preterms. This volume increase was associated with improved cognitive performance of the preterm sample (Parker et al., 2008).

Not only structural but also functional characteristics of the neural language organization are thought to relate to language performance. More left-sided language organization is associated with higher Verbal-IQ or better verbal performance (Everts et al, 2009; Hirnstein et al. 2014). Not only language measures but also intelligence in general seems to interact with language lateralization, as more intelligent children show an increased asymmetry of language to the left hemisphere (Schmithorst and Holland, 2007). Accordingly, in the control sample of the present study, a more leftsided language organization was associated with a higher Full-Scale IQ, reflecting a cognitive benefit in case of strongly lateralized language organization. This result, however, has to be interpreted with caution as it did not survive a conservative Bonferroni correction for multiple testing.

In contrast to our results, various studies have shown group differences in language organization between very preterm and controls, independent of age (Ment et al., 2006; Peterson et al., 2002; Rushe et al., 2004). The divergent findings might reflect the different age ranges studied or the varying demands of $\mathrm{fMRI}$ language tasks across studies. A further reason might be that the children examined in this study had no or minimal complications at birth, IQ within the normal range and moderate to high socioeconomic background. It is possible that the relatively healthy preterm children in our sample are more likely to show a catch-up effect with regard to functional development than children with more severe neonatal problems.

A potential limitation of the study lies in the significant $I Q$ and language performance difference between very preterm born children and controls. This difference does not reflect deficient 
LANGUAGE ORGANIZATION IN VERY PRETERM CHILDREN

language processing in very preterm born children but is due to the above-average performance of the control sample. A control group showing above-average language performance is a common problem and has to be considered when interpreting study results (Ment et al., 2006; Peterson et al., 2002). Further, considering the low response rate as well as the stringent inclusion criteria applied in this study, the present sample does not represent the population of very preterm born children in its full variance. Lastly, the results of this study are based on cross-sectional data. Longitudinal studies are required to give insight into the developmental path of language. Examining a wider age range and replicating the findings with $\mathrm{fMRI}$ measuring different aspects of language, i.e. language comprehension, semantics or vocabulary, may provide broader understanding of the development of language organization in the prematurely born child.

To conclude, the present data suggest that very preterm born children retain atypical bilateral language organization longer than term born controls, which may be explained by a delay in neural language organization due to very premature birth. 
LANGUAGE ORGANIZATION IN VERY PRETERM CHILDREN

References

Andersson, J. L., Hutton, C., Ashburner, J., Turner, R., \& Friston, K. (2001). Modeling geometric deformations in EPI time series. Neuroimage, 13, 903-919. doi: 10.1006/nimg.2001.0746

Barre, N., Morgan, A., Doyle, L. W., \& Anderson, P. J. (2011). Language abilities in children who were very preterm and/or very low birth weight: a meta-analysis. Journal of Pediatrics, 158, 766774. doi: 10.1016/j.jpeds.2010.10.032

Bates, E. (1999). Language and the infant brain. Journal of Commuication Disorders, 32, $195-205$.

Carreiras, M., Seghier, M.L., Baquero, S., Estéves, A., Lozano, A., Devlin, J.T., \& Price, C.J. (2009). An anatomical signature for literacy. Nature, 461, 983-986. 10.1038/nature08461

Counsell, S., Rutherford, M.A., Cowan, F.M., \& Edwards, A.D. (2003). Magnetic resonance imaging of preterm brain injury. Archives of Disease in Childhood. Fetal and Neonatal Edition, 88, 269274. $10.1136 /$ fn.88.4.F269

Crawford, J. R., Anderson, V., Rankin, P. M., \& MacDonald, J. (2010). An index-based short-form of the WISC-IV with accompanying analysis of the reliability and abnormality of differences. British Journal of Clinical Psychoogyl, 49, 235-258. doi: 10.1348/014466509X455470

Delis, D. C., Kaplan, E., \& Kramer, J. (2001). Delis Kaplan Executive Function System. San Antonio: TX: The Psychological Corporation.

Everts, R., Lidzba, K., Wilke, M., Kiefer, C., Mordasini, M., Schroth, G., ... Steinlin, M. (2009). Strengthening of laterality of verbal and visuospatial functions during childhood and adolescence. Human Brain Mapping, 30, 473-483. doi: 10.1002/hbm.20523

Everts, R., Lidzba, K., Wilke, M., Kiefer, C., Wingeier, K., Schroth, G., ... Steinlin, M. (2010). Lateralization of cognitive functions after stroke in childhood. Brain Injuries, 24, 859-870. doi: $10.3109 / 02699051003724978$

Foster-Cohen, S., Edgin, J. O., Champion, P. R., \& Woodward, L. J. (2007). Early delayed language development in very preterm infants: evidence from the MacArthur-Bates CDI. Journal of Child Language, 34, 655-675.

Gozzo, Y., Vohr, B., Lacadie, C., Hampson, M., Katz, K. H., Maller-Kesselman, J., ... Ment, L. R. (2009). Alterations in neural connectivity in preterm children at school age. Neuroimage, 48, 458-463. doi: 10.1016/j.neuroimage.2009.06.046 
LANGUAGE ORGANIZATION IN VERY PRETERM CHILDREN

Gressens, P. (2000). Mechanisms and disturbances of neuronal migration. Pediatric Research, 48, 725-730. doi:10.1203/00006450-200012000-00004

Hirnstein, M., Hugdahl, K., \& Hausmann, M. (2014). How brain asymmetry relates to performance - a large-scale dichotic listening study. Frontoers in Psychology, 2, 4:997. doi: 10.3389/fpsyg.2013.00997

Holland, S. K., Plante, E., Weber Byars, A., Strawsburg, R. H., Schmithorst, V. J., \& Ball, W. S., Jr. (2001). Normal fMRI brain activation patterns in children performing a verb generation task. Neuroimage, 14, 837-843. doi: 10.1006/nimg.2001.0875

Holland, S. K., Vannest, J., Mecoli, M., Jacola, L. M., Tillema, J. M., Karunanayaka, P. R., ... Byars, A. W. (2007). Functional MRI of language lateralization during development in children. International Journal of Audiology, 46, 533-551. doi: 10.1080/14992020701448994

Johnson, S., Hennessy, E., Smith, R., Trikic, R., Wolke, D., \& Marlow, N. (2009). Academic attainment and special educational needs in extremely preterm children at 11 years of age: the EPICure study. Archives of Disease in Childhood. Fetal and Neonatal Edition, 94, F283289. doi: $10.1136 /$ adc. 2008.152793

Lenhard, W., Schneider, W. (2006). ELFE 1-6: Ein Leseverständnistest für Erst- bis Sechstklässler. Göttingen: Hogrefe.

Ment, L. R., Peterson, B. S., Vohr, B., Allan, W., Schneider, K. C., Lacadie, C., ... Constable, R. T. (2006). Cortical recruitment patterns in children born prematurely compared with control subjects during a passive listening functional magnetic resonance imaging task. Journal of Pediatrics, 149, 490-498. doi: 10.1016/j.jpeds.2006.06.007

Myers, E. H., Hampson, M., Vohr, B., Lacadie, C., Frost, S. J., Pugh, K. R., ... Ment, L. R. (2010). Functional connectivity to a right hemisphere language center in prematurely born adolescents. Neuroimage, 51, 1445-1452. doi: 10.1016/j.neuroimage.2010.03.049

Nosarti, C., Rushe, T.M., Woodruff, P.W., Stewart, A.L., Rifkin, L., \& Murray, R.M. (2004). Corpus callosum size and very preterm birth: relationship to neuropsychological outcome. Brain, 127, 2080-2089. doi: 10.1093/brain/awh230

Parker, J., Mitchell, A., Kalpakidou, A., Walshe, M., Jung, H.-Y., Nosarti, C., Santosh, P., Rifkin, L., Wyatt, J., Murray, R. M., \& Allin, M. (2008). Cerebellar growth and behavioural \& 


\section{Developmental Neuropsychology}

LANGUAGE ORGANIZATION IN VERY PRETERM CHILDREN

neuropsychological outcome in preterm adolescents. Brain, 131, 1344-1351.

doi:10.1093/brain/awn062

Peterson, B. S., Vohr, B., Kane, M. J., Whalen, D. H., Schneider, K. C., Katz, K. H., ... Ment, L. R. (2002). A functional magnetic resonance imaging study of language processing and its cognitive correlates in prematurely born children. Pediatrics, 110, 1153-1162.

Ritter, B. C., Nelle, M., Perrig, W., Steinlin, M., \& Everts, R. (2013). Executive functions of children born very preterm--deficit or delay? European Journal of Pediatrics, 172, 473-483. doi: $10.1007 / \mathrm{s} 00431-012-1906-2$

Rushe, T. M. (2010). Language function after preterm birth. In M. R. Nosarti C, Hack M (Ed.), Neurodevelopmental Outcomes of Preterm Birth (pp. 176-184). Cambridge: Cambridge University Press.

Rushe, T. M., Temple, C. M., Rifkin, L., Woodruff, P. W., Bullmore, E. T., Stewart, A. L., ... Murray, R. M. (2004). Lateralisation of language function in young adults born very preterm. Archives of Disease in Childhood. Fetal and Neonatal Edition 89, F112-118.

Saigal, S., \& Doyle, L. W. (2008). An overview of mortality and sequelae of preterm birth from infancy to adulthood. Lancet, 371, 261-269. doi: 10.1016/S0140-6736(08)60136-1

Sansavini, A., Guarini, A., Alessandroni, R., Faldella, G., Giovanelli, G., \& Salvioli, G. (2007). Are early grammatical and phonological working memory abilities affected by preterm birth? Journal of Communication Disorders, 40, 239-256. doi: 10.1016/j.jcomdis.2006.06.009

Schmithorst, V.J., \& Holland, S.K. (2007). Sex differences in the development of neuroanatomical functional connectivity underlying intelligence found using Bayesian connectivity analysis. Neuroimage, 35, 406-419. doi: 10.1016/j.neuroimage.2006.11.046.

Szaflarski, J. P., Rajagopal, A., Altaye, M., Byars, A. W., Jacola, L., Schmithorst, V. J., ... Holland, S. K. (2012). Left-handedness and language lateralization in children. Brain Research, 1433, 8597. doi: 10.1016/j.brainres.2011.11.026

Thompson, P.M., Giedd, J.N., Woods, R.P., MacDonald, D., Evans, A.C., \& Toga, A.W. (2000). Growth patterns in the developing brain detected by using continuum mechanical tensor maps. Nature, 404, 190-193. doi:10.1038/35004593 
LANGUAGE ORGANIZATION IN VERY PRETERM CHILDREN

van Noort-van der Spek, I. L., Franken, M. C., \& Weisglas-Kuperus, N. (2012). Language functions in preterm-born children: a systematic review and meta-analysis. Pediatrics, 129, 745-754. doi: 10.1542/peds.2011-1728

Wilke, M., Holland, S. K., Altaye, M., \& Gaser, C. (2008). Template-O-Matic: a toolbox for creating customized pediatric templates. Neuroimage, 41, 903-913. doi: 10.1016/j.neuroimage.2008.02.056

Wilke, M., \& Lidzba, K. (2007). LI-tool: a new toolbox to assess lateralization in functional MR-data. Journal of Neuroscience Methods, 163, 128-136. doi: 10.1016/j.jneumeth.2007.01.026

Wilke, M., Lidzba, K., Staudt, M., Buchenau, K., Grodd, W., \& Krägeloh-Mann, I. (2006). An fMRI test battery for assessing hemispheric language dominance in children. Neuroimage, 32, 400-410. doi: 10.1016/j.neuroimage.2006.03.012.

Wolke, D., \& Meyer, R. (1999). Cognitive status, language attainment, and prereading skills of 6-yearold very preterm children and their peers: the Bavarian Longitudinal Study. Developmental Medicine \& Child Neurology, 41, 94-109. 
Running head: LANGUAGE ORGANIZATION IN VERY PRETERM CHILDREN

Figure Legends

Figure 1. A) fMRI task activation of very preterm born children and term born controls during vowel detection task (activation $>$ baseline condition, $\mathrm{p}<.05$, FWE-corrected, threshold $\mathrm{k}>60$ voxels). B) fMRI task activation of younger and older very preterm born children and term born controls during vowel detection task (activation $>$ contrast condition, $p<.001$, threshold $k>20$ voxels). Results are shown in render and slice view (slices with main activation clusters are shown). $L=$ left, $R=$ right.

Figure 2. Correlation between temporal lateralization index and age (controlled for Full-scale IQ and SES) in very preterm born children and term born controls. The solid line refers to very preterm born children, the dashed line refers to term born controls, the transparent grey area indicates bilateral lateralization.

URL: http://mc.manuscriptcentral.com/hdvn Email: dlmolfese@mac.com 
A)
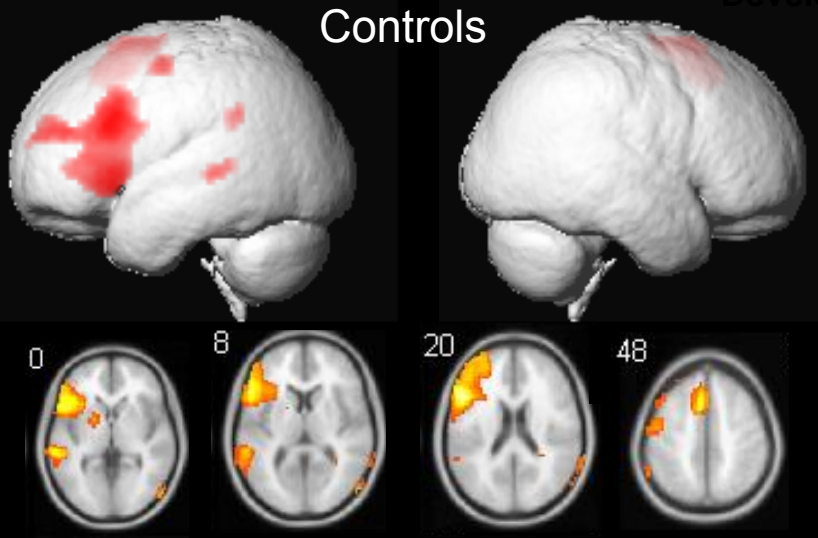

B)
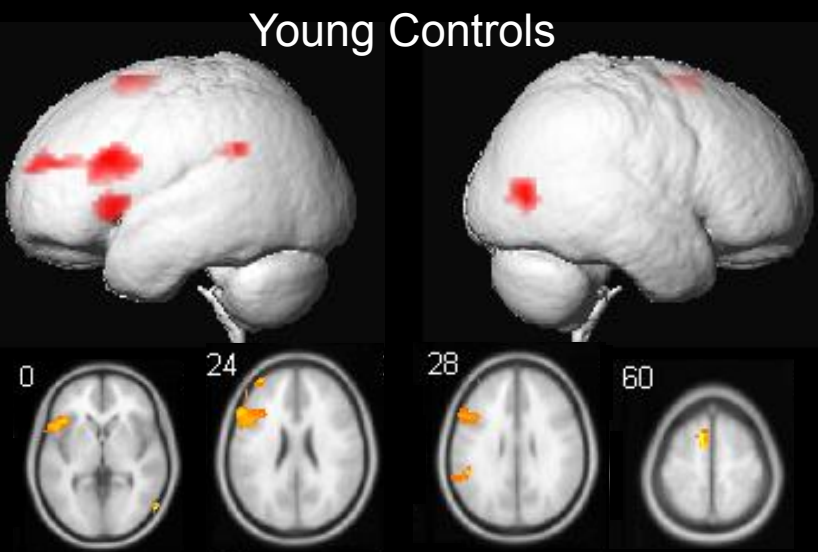
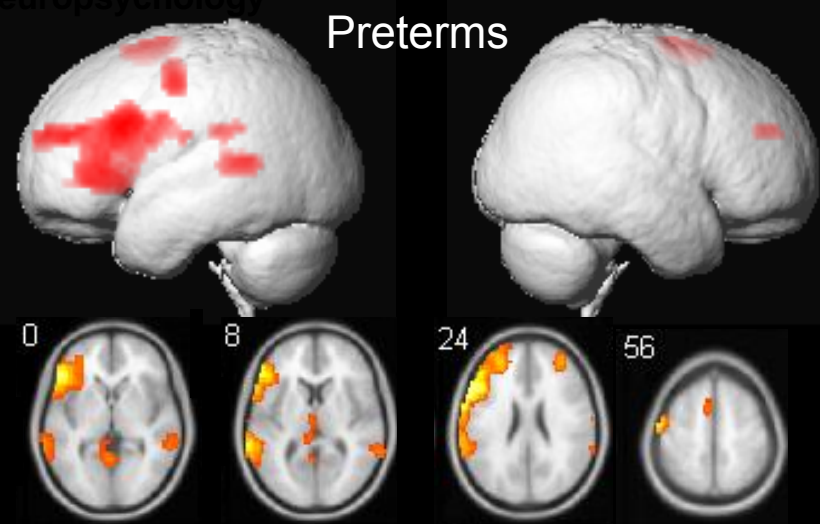

Young Preterms
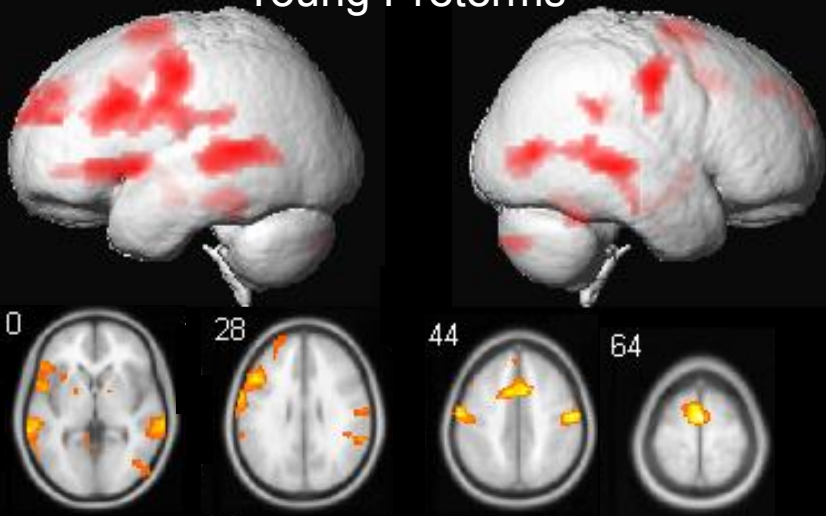
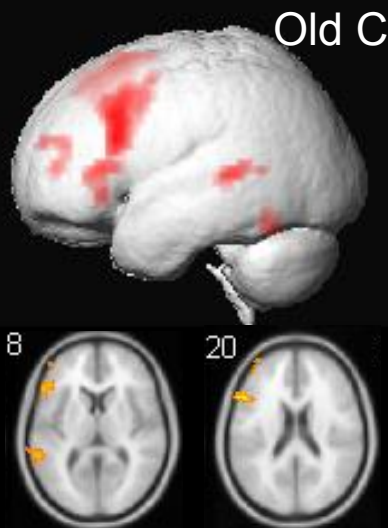
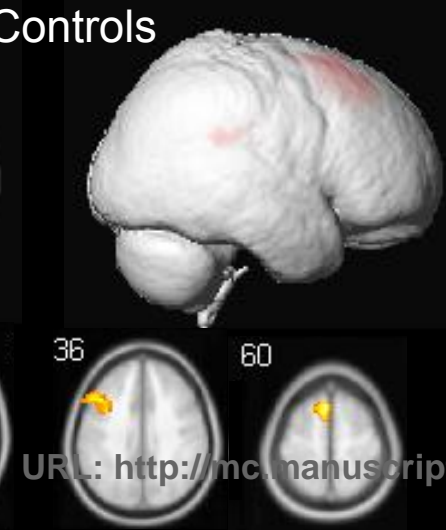

T-value

10
8

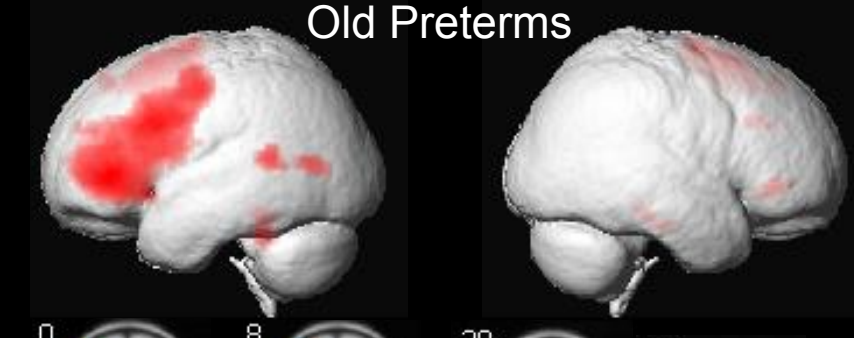

6

4

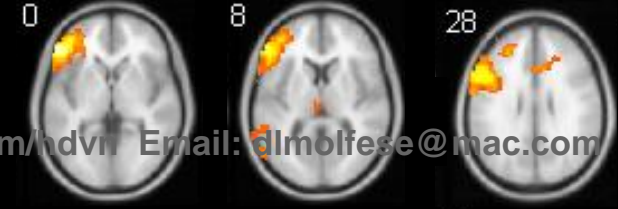

0

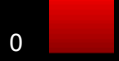




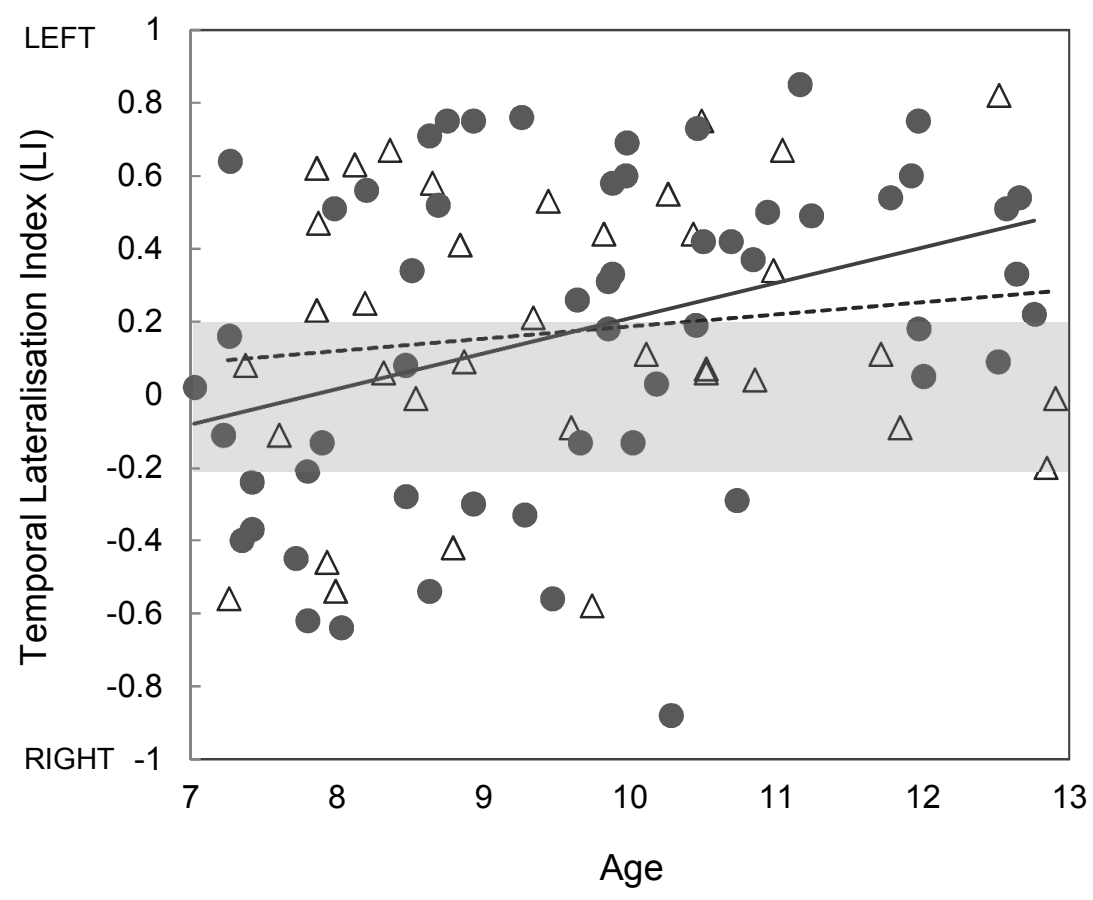

$\triangle$ Term born controls $(r=.076, p=.330)$

- Very preterm born children $(r=.297, p=.015)$ 
Table 1. Demographic, cognitive and imaging data for very preterm born children and term born controls and for young and old age groups.

\begin{tabular}{|c|c|c|c|c|c|c|c|c|c|}
\hline & \multicolumn{2}{|c|}{ Total Group } & \multirow[b]{2}{*}{$U / x^{2}$} & \multirow[b]{2}{*}{$p$} & \multicolumn{2}{|c|}{ Controls } & \multicolumn{2}{|c|}{ Preterms } & \multirow{2}{*}{$\begin{array}{c}\text { Drop outs } \\
\quad(n=8)\end{array}$} \\
\hline & $\begin{array}{c}\text { Controls } \\
(n=38)\end{array}$ & $\begin{array}{l}\text { Preterms } \\
(n=56)\end{array}$ & & & $\begin{array}{c}\text { Younger } \\
(n=12)\end{array}$ & $\begin{array}{c}\text { Older } \\
(n=13)\end{array}$ & $\begin{array}{c}\text { Younger } \\
(n=19)\end{array}$ & $\begin{array}{c}\text { Older } \\
(n=19)\end{array}$ & \\
\hline Age & $9.6(1.6)$ & $9.7(1.7)$ & -0.30 & .762 & $7.9(0.3)$ & $11.4(0.9)$ & $7.8(0.5)$ & $11.6(0.8)$ & $9.6(2.1)$ \\
\hline Age range & 7.3-12.9 & $7.0-12.8$ & - & - & 7.3-8.3 & $10.4-12.9$ & $7.0-8.6$ & $10.5-12.8$ & $7.8-12.9$ \\
\hline $\operatorname{Sex}(f, m)$ & 19,19 & 28,28 & - & - & 8,4 & 5,8 & 10,9 & 8,11 & 4,4 \\
\hline SES mother $(1,2,3,4)$ & $0,13,8,17$ & $0,40,11,5$ & 595 & $<.001^{* *}$ & $0,3,2,7$ & $0,8,0,5$ & $0,12,4,3$ & $0,17,2,0$ & $0,6,2,0$ \\
\hline SES father $(1,2,3,4)$ & $1,12,4,21$ & $0,40,3,13$ & 683 & $.001^{* *}$ & $0,5,1,6$ & $1,3,1,8$ & $0,13,1,5$ & $0,14,2,3$ & $0,4,3,1$ \\
\hline Gestational age (weeks) & - & $30.0(2.4)$ & - & - & - & - & $30.2(2.0)$ & $29.6(2.1)$ & - \\
\hline Birth weight (gram) & - & $1276.2(372.6)$ & - & - & 8 & - & $1337.6(372.4)$ & $1218.9(390.7)$ & - \\
\hline Full-scale IQ (WISC-IV) $)^{1}$ & $109.5(7.7)$ & $101.1(8.7)$ & 493 & $<.001^{* *}$ & $109.7(8.4)$ & $110.9(8.5)$ & $102.3(8.2)$ & $101.8(8.5)$ & $111.4(6.8)$ \\
\hline Verbal-IQ (WISC-IV) $^{1}$ & $111.6(11.6)$ & $101.9(9.4)$ & 580 & $<.001^{* *}$ & $111.5(9.5)$ & $115.2(12.2)$ & $103.1(9.1)$ & $102.8(10.3)$ & $110.0(7.5)$ \\
\hline Verbal fluency (FAS) ${ }^{2}$ & $10.7(2.5)$ & $9.5(2.4)$ & 742 & $.020^{*}$ & $10.8(2.7)$ & $10.3(2.2)$ & $9.2(2.3)$ & $9.7(2.0)$ & $9.7(1.9)$ \\
\hline Word reading $(E L F E)^{3}$ & $54.6(9.9)$ & $49.1(9.1)$ & 659 & $.039^{*}$ & $51.5(10.0)$ & $56.2(10.8)$ & $47.5(10.4)$ & $50.1(9.1)$ & $50.6(5.6)$ \\
\hline Sentence reading $(E L F E)^{3}$ & $53.9(9.4)$ & $49.5(8.6)$ & 608 & .060 & $54.1(10.1)$ & $53.3(12.3)$ & $49.9(9.4)$ & $49.1(8.4)$ & $51.8(5.4)$ \\
\hline Frontal LI & $0.532(0.3)$ & $0.499(0.3)$ & 975 & .490 & $0.500(0.4)$ & $0.630(0.4)$ & $0.430(0.4)$ & $0.579(0.2)$ & - \\
\hline Temporal LI & $0.162(0.4)$ & $0.177(0.4)$ & 1019 & .729 & $0.056(0.4)$ & $0.230(0.3)$ & $-0.051(0.4)$ & $0.394(0.3)$ & - \\
\hline Left frontal PSC & $0.059(0.2)$ & $0.053(0.3)$ & 1026 & .770 & $0.004(0.2)$ & $-0.010(0.2)$ & $0.078(0.3)$ & $0.063(0.3)$ & - \\
\hline Right frontal PSC & $0.004(0.2)$ & $-0.003(0.3)$ & 1042 & .865 & $-0.022(0.2)$ & $-0.071(0.2)$ & $0.043(0.3)$ & $-0.006(0.3)$ & - \\
\hline Left temporal PSC & $0.062(0.2)$ & $0.092(0.3)$ & 995 & .595 & $0.002(0.1)$ & $0.013(0.2)$ & $0.194(0.4)$ & $0.073(0.3)$ & - \\
\hline Right temporal PSC & $0.075(0.2)$ & $0.062(0.4)$ & 1022 & .746 & $0.054(0.2)$ & $0.005(0.2)$ & $0.192(0.5)$ & $0.044(0.3)$ & - \\
\hline
\end{tabular}

URL: http://mc.manuscriptcentral.com/hdvn Email: dlmolfese@mac.com 
Table 2. Correlations between Age, LI, PSC, and neuropsychological performance in very preterm born children and term born controls.

\begin{tabular}{|c|c|c|c|c|c|c|c|}
\hline Preterms & & Age & $\begin{array}{c}\text { Full-Scale IQ } \\
\text { (WISC-IV) }\end{array}$ & $\begin{array}{c}\text { Verbal IQ } \\
\text { (WISC-IV) }\end{array}$ & $\begin{array}{c}\text { Verbal } \\
\text { fluency } \\
\text { (FAS) }\end{array}$ & $\begin{array}{c}\text { Word reading } \\
\text { (ELFE) }\end{array}$ & $\begin{array}{c}\text { Sentence } \\
\text { reading } \\
(E L F E)\end{array}$ \\
\hline \multirow{13}{*}{ Controls } & Frontal LI & 0.015 & 0.133 & 0.138 & -0.150 & 0.042 & 0.191 \\
\hline & Temporal LI & $0.355^{\star \star}$ & -0.067 & -0.102 & 0.108 & $0.256^{*}$ & 0.093 \\
\hline & Left frontal PSC & 0.066 & -0.166 & -0.169 & 0.13 & -0.042 & 0.153 \\
\hline & Right frontal PSC & 0.022 & -0.193 & -0.161 & -0.040 & -0.201 & 0.026 \\
\hline & Left temporal PSC & 0.003 & -0.029 & 0.016 & 0.119 & -0.057 & 0.126 \\
\hline & Right temporal PSC & -0.066 & -0.107 & -0.004 & 0.046 & -0.172 & -0.025 \\
\hline & & & & & & & \\
\hline & Frontal LI & 0.218 & $0.299^{*}$ & 0.161 & 0.036 & 0.164 & 0.137 \\
\hline & Temporal LI & 0.090 & 0.168 & 0.048 & 0.150 & -0.075 & $-0.295^{\star}$ \\
\hline & Left frontal PSC & 0.063 & -0.247 & -0.082 & -0.092 & -0.008 & 0.066 \\
\hline & Right frontal PSC & -0.060 & $0.281^{*}$ & -0.040 & 0.037 & -0.229 & -0.066 \\
\hline & Left temporal PSC & 0.032 & -0.210 & 0.057 & 0.085 & -0.063 & -0.188 \\
\hline & Right temporal PSC & -0.081 & -0.079 & 0.043 & 0.039 & -0.164 & -0.075 \\
\hline
\end{tabular}

$<-0.2$, bilateral $\mathrm{LI}-0.2$ to 0.2 ); PSC = percent signal change; IQ = Intelligence quotient. 